\title{
Principal Possibility of the Successful Nowcast and Short-Term Forecast in the Middle Atmosphere Based on the Observed UV Irradiance
}

\author{
T. Egorova, ${ }^{1}$ E. Rozanov, ${ }^{1,2}$ A. V. Shapiro, ${ }^{1,2}$ and W. Schmutz ${ }^{1}$ \\ ${ }^{1}$ Physikalisch-Meteorologisches Observatorium Davos/ World Radiation Center, 7260 Davos, Switzerland \\ ${ }^{2}$ Institute for Atmospheric and Climate Science, Swiss Federal Institute of Technology Zurich, 8092 Zurich, Switzerland
}

Correspondence should be addressed to T. Egorova, t.egorova@pmodwrc.ch

Received 10 November 2011; Accepted 11 January 2012

Academic Editor: M. V. Klimenko

Copyright ( $) 2012$ T. Egorova et al. This is an open access article distributed under the Creative Commons Attribution License, which permits unrestricted use, distribution, and reproduction in any medium, provided the original work is properly cited.

\begin{abstract}
We have applied chemistry-climate model (CCM) SOCOL to simulate the distribution of the temperature and gas species in the upper stratosphere and mesosphere. As an input for the simulation, we employ daily spectral solar UV irradiance measured by SUSIM instrument onboard UARS satellite in January 1992. We have carried out an ensemble of nine 1-month long simulations using slightly different initial states of the atmosphere. We have compared the obtained time evolution of the simulated species and temperature with available satellite measurements. The obtained results allowed us to define the areas where the nowcast and short-term forecast of the atmospheric species with CCM SOCOL could be successful.
\end{abstract}

\section{Introduction}

The perturbation of the solar activity is able to induce sub-stantial changes in the Earth environment, which turn out to be important for the space operations [1], radio-wave propagation, GPS functioning, and many other aspects of the mankind activity [2]. Therefore the nowcast and short-term forecast of the space weather based on the different observational data gained recently a lot of attention. Among other elements of the space weather, it is of interest to understand and predict the state of the neutral compounds in the middle atmosphere, which determines in part the reaction of the ionosphere to the variability of the Sun activity. An important aspect of this issue is an evaluation and prediction of the middle atmosphere response to the solar ultraviolet irradiance variability. The composition and temperature in the middle atmosphere are defined by the photolysis and heating rates [3], which depend directly on the solar activity and also by complicated nonlinear atmospheric dynamics and connected with it advective and turbulent transport of the species. For the solar UV irradiance high-quality observation data are available from a variety of satellite instruments in the past
[4], and there will be more data available in real time in the future. For example, the LYRA instrument onboard PROBA-2 satellite will provide the solar irradiance for several wavelengths important for the middle atmosphere in real time [5]. These data together with solar irradiance measurements available from the SORCE experiment (http://earthobservatory.nasa.gov/Library/SORCE/sorce_06 .html) provide a solid basis for the nowcast of neutral compounds in the middle atmosphere. The statistical forecasting technique developed during the last decade [6] can also provide reliable estimates of the solar irradiance variability in 10-day time frame and facilitate the short-term forecast of the middle atmosphere state based on the state-of-the-art modeling of atmospheric dynamics and chemistry. However, it has not been clearly shown yet which part of the species and temperature changes in the middle atmosphere is defined by the solar irradiance variability and what is the contribution of the nonlinear transport. There is some evidence that the ozone and temperature depend on the solar irradiance variability during known 27-day solar rotation cycle (e.g., [7]), but it was also pointed out by [8] that the correlation between solar irradiance and ozone in the middle atmosphere strongly depends on the atmospheric 
meteorological state implying that the atmospheric dynamics and transport play an important role in the response of the middle atmosphere to solar irradiance variability. Therefore, for a successful nowcast and short-term forecast, we need to show that (i) the quantity under consideration is sensitive to the solar irradiance variability and (ii) the contribution of the dynamical noise is reasonably small. To answer these questions, we applied a chemistry-climate model and carried out 1-month long ensemble simulation of the middle atmosphere for January 1992. The model description and experimental set-up will be described in Section 2. In Section 3, we present the results of our simulations, and some conclusions and outlook are presented in Section 4.

\section{Model Description and Experimental Set-Up}

The global three-dimensional CCM SOCOL was developed at the Physical-Meteorological Observatory (Davos, Switzerland) in collaboration with ETH Zürich (Switzerland) and Voeikov Main Geophysical Observatory (St. Petersburg, Russia) [9]. The CCM SOCOL is a combination of the middle atmosphere version of the European Center/Hamburg Model 4 General Circulation Model (MA-ECHAM4) [10, 11] with a modified version of the University of Illinois at Urbana-Champaign three-dimensional CTM Model for the Evaluation of Ozone Trends (MEZON) [12, 13]. The horizontal resolution of SOCOL is $3.75^{\circ} \times 3.75^{\circ}$. Vertically, this model is divided into 39 levels in a hybrid sigma/pressure coordinate system and extends from the surface to $0.01 \mathrm{hPa}$ $(\sim 80 \mathrm{~km})$. The CTM MEZON calculates the distributions of concentrations of 45 trace gases from the major atmospheric groups, which are determined by 118 gas phase reactions, 33 photolytic reactions, and 16 heterogeneous reactions.

The transport of trace gases in the CTM MEZON is calculated using the advection scheme [14]. The time step for the dynamic core of the MA-ECHAM4 model is $15 \mathrm{~min}$. Parameters of physical processes are calculated every $2 \mathrm{~h}$. The time step of the CTM MEZON is also $2 \mathrm{~h}$. The model parts of the CCM SOCOL (MEZON and MA-ECHAM4) exchange data on the fields of major dynamical variables and radiatively active gases every $2 \mathrm{~h}$. Concentrations of ozone, methane, nitrous oxide, chlorofluorocarbons, and stratospheric water vapor are transferred from MEZON to MA-ECHAM4, and three-dimensional distributions of temperature, water vapor concentration, and zonal, meridional, and vertical components of wind velocity are transferred from ECHAM4 to MEZON. Thus, the interactive character of the CCM SOCOL makes it possible to correctly include the main feedbacks between dynamical, advective, photochemical, and radiative processes. The original version of SOCOL is described in detail in [9].

Nine one-month long model runs have been carried out for 1992 conditions. The difference between ensemble members consists of slightly different initial state of the atmosphere which was achieved by changing the concentration of $\mathrm{CO}_{2}$ in the range of $0.1 \%$. The boundary conditions and external forcing are identical for all ensemble members. The sea surface temperature and the sea ice distributions have

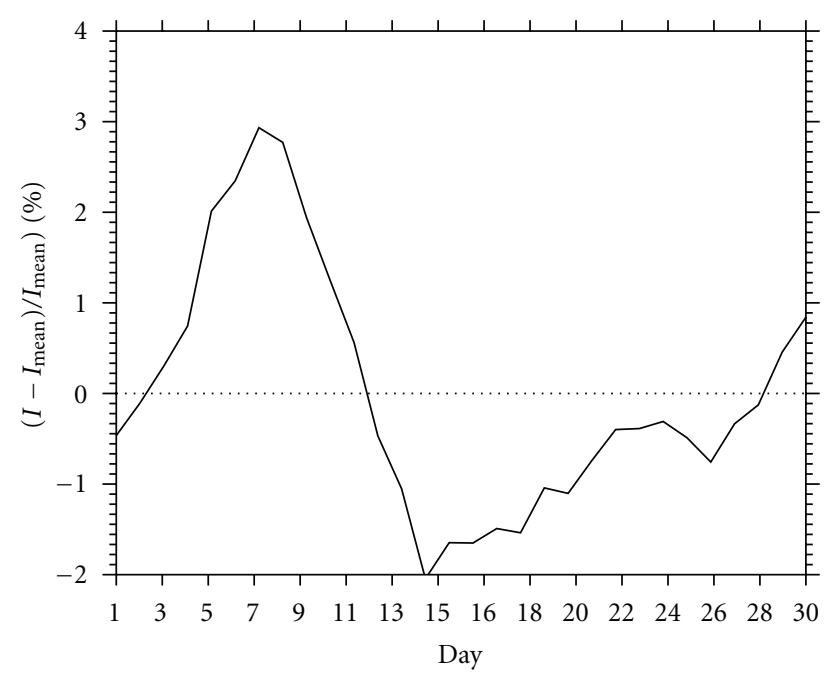

Figure 1: Deviation of the solar irradiance at $205 \mathrm{~nm}$ from its monthly mean for January 1992. The data are from SUSIM instrument onboard UARS satellite.

been taken from [15], which represents climatology over the last 20 years. The stratospheric aerosol, greenhouse gas and ozone destroying substances concentrations, and the sources of $\mathrm{NO}_{x}$ and $\mathrm{CO}$ are the same as in $[12,16]$. The coefficients for photolysis and heating rates calculations in the model have been updated daily using the solar energy spectrum obtained by the SUSIM instrument onboard of the UARS satellite for the year 1992. SUSIM UARS version 21 L3BS irradiance data were acquired from SUSIM UARS $\mathrm{ftp}$-site \{ftp susim.nrl.navy.mil\}. The radiation in visible and nearinfrared parts of the spectrum was kept unchanged. From the described simulation daily and zonal mean temperature, ozone, hydroxyl, and water vapor mixing ratio have been stored for each ensemble member, which allows analyzing the response of these quantities to the solar irradiance variability during sun rotation cycle.

The solar irradiance variability at $205 \mathrm{~nm}$ during January 1992 applied for the calculation is illustrated in Figure 1. During the considered year, the solar activity was rather high and due to nonhomogeneity in the Sun spots distribution, the solar irradiance increased from January 1 reaching its maximum on January 7 . Then the solar irradiance reached its minimum on January 14 and after that it has been steadily increasing until the end of January.

\section{Results}

To estimate the dependency of the simulated quantities on the solar irradiance variability, we calculated crosscorrelation functions between the ensemble mean of hydroxyl, ozone, water vapor, temperature, and solar irradiance at $205 \mathrm{~nm}$ with time lag \pm 15 days. Time lag is a time shift between one of the chemical or thermal characteristics of the atmosphere and solar spectral irradiance. The absolute maximum of the cross-correlation function is presented in Figure 2 for every latitude and altitude. It is well known 

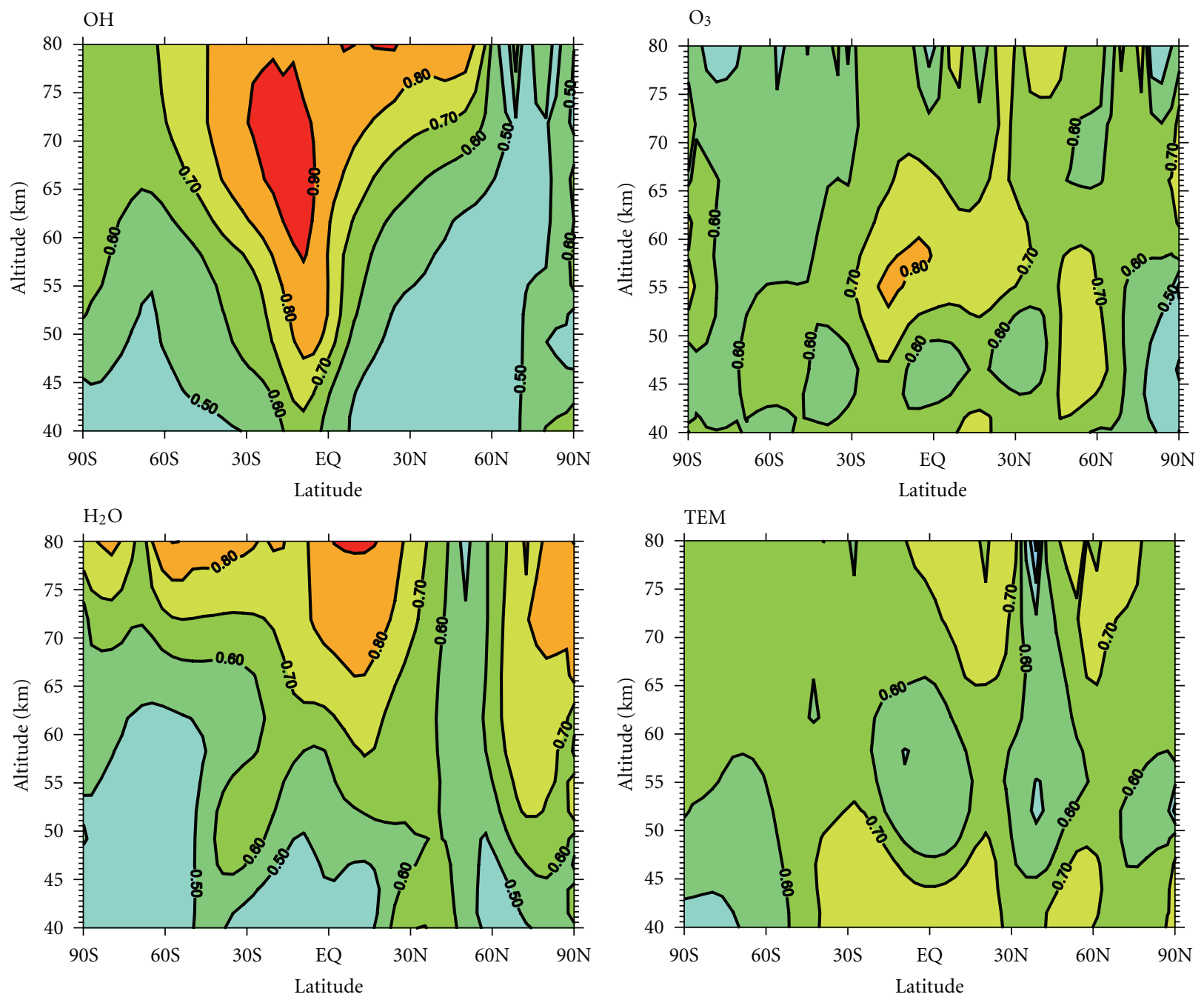

Figure 2: Maximum of the cross-correlations between simulated ensemble mean quantities and solar irradiance at $205 \mathrm{~nm}$.

$[3,7,17]$ that an increase of the solar irradiance in Lymanalpha line leads to an enhancement of hydroxyl due to increased photolysis of the water vapor. The obtained results show that this process is clearly significant in the mesosphere leading to rather high correlation between solar irradiance and hydroxyl and water vapor. The correlation coefficients are the highest $(\sim 0.8)$ in the tropical area and in the upper mesosphere. Over the northern high latitudes, we cannot expect any correlations, because the solar irradiance cannot reach polar night areas; however some correlations can be induced by the dynamical changes resulting from the ozone and temperature perturbations. The ozone production due to photolysis of oxygen in Schumann-Runge bands and Herzberg continuum intensifies with increase of the solar irradiance in the lower mesosphere and most of the stratosphere; however in the rest of the mesosphere the ozone and solar irradiance anticorrelates due to enhanced ozone destruction by hydroxyl $[18,19]$. These two processes are responsible for rather high positive and negative correlation between ozone and solar irradiance. The maximum correlations occur in the tropical lower mesosphere and over the northern middle latitudes. The latter presumably reflects the changes in the atmospheric dynamics and transport. The correlation between temperature and solar irradiance is explained by the additional direct (due to increased energy flux) and indirect (due to ozone increase) heating. The highest correlation between temperature and solar irradiance takes place in the upper mesosphere and upper stratosphere. The presented results confirm that the atmospheric state is sensitive to the perturbations in the solar irradiance.

To estimate the sensitivity of the atmospheric response to the atmospheric state, we calculated mean absolute deviation among our nine ensemble members for any particular day and location. The averaged mean absolute deviation over 30 days of the model run reflects the sensitivity of the model results to the atmospheric states. A small mean absolute deviation means that all ensemble members demonstrate similar behavior in reproducing the time evolution of the atmospheric state, while a large mean absolute deviation indicates that the dynamical noise dominates and the simulated time evolution of the atmospheric state is not robust. The mean absolute deviations for hydroxyl, ozone, 

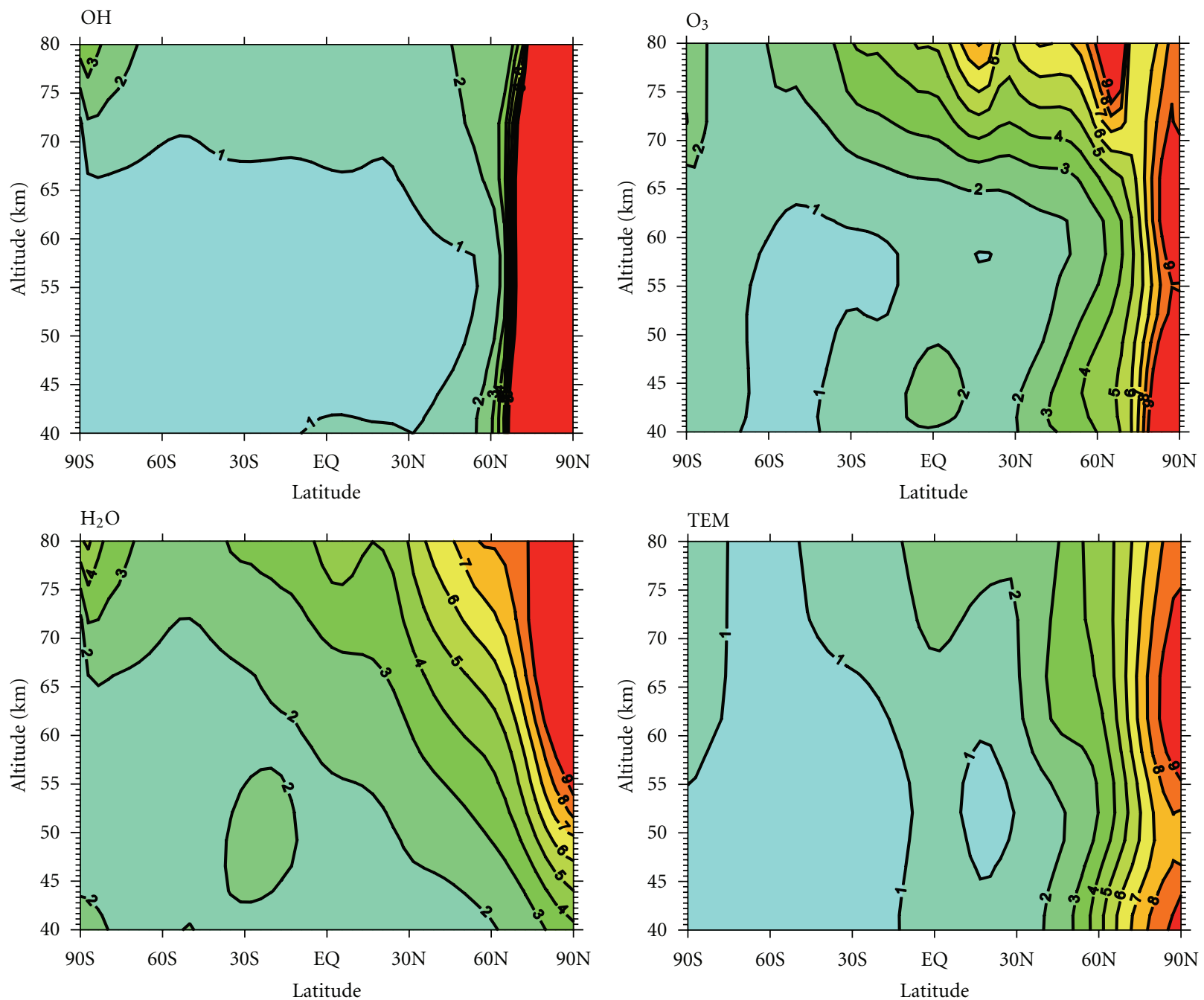

FIgURE 3: Mean absolute deviation among the ensemble members averaged over 30-day interval. Mean absolute deviation for species is shown in percent relative to the mean mixing ratio. Mean absolute deviation for the temperature is given in $(\mathrm{K})$.

water vapor, and temperature are presented in Figure 3. The obtained results show that the nonlinear behavior is mostly confined to the northern middle and high latitudes, where the atmospheric dynamics is the most active during boreal winter. Over the tropics and Southern hemisphere, the time evolution of the atmospheric state is more robust.

Using the combination of two above-analyzed criteria, we can define the areas where the probability of successful nowcast and short-term forecast of the considered quantities based on the solar irradiance data is higher. For these areas, we request the correlation coefficient to be higher than 0.7 and mean absolute deviation to be lower than $4 \%$ for considered species and lower than $4 \mathrm{~K}$ for the temperature. The obtained latitude-altitude cross-sections of these areas are depicted in Figure 4 for all considered species. From the obtained results, we can conclude that the temperature can be successfully predicted in the upper tropical stratosphere and mesosphere. For the water vapor and hydroxyl this area confines mostly to the tropical mesosphere and upper mesosphere over the southern middle and high latitudes. The ozone can be successfully predicted in the tropical lower mesosphere and upper stratosphere over the northern middle latitudes. It is of great interest to check our conclusions using satellite data obtained during January 1992. For this purpose, we made use of the ozone daily data measured by HALOE instrument onboard UARS satellite. These data are available from HALOE home page (http://haloe.gats-inc.com/home/index.php). Unfortunately, the quality of the ozone data in the mesosphere is rather poor; therefore we compare our model results with HALOE ozone only near the stratopause. For the comparison, we used satellite data collected during sunrise events, which cover northern middle latitudes $\left(\sim 40^{\circ} \mathrm{N}-50^{\circ} \mathrm{N}\right)$ from January 5 to January 12 . The zonal daily mean simulated ozone mixing ratio is presented in Figure 5 together with smoothed HALOE data. Despite some differences, all ensemble members reveal an increase of ozone mixing ratio from January 2 to January 7 and a subsequent decrease, which 

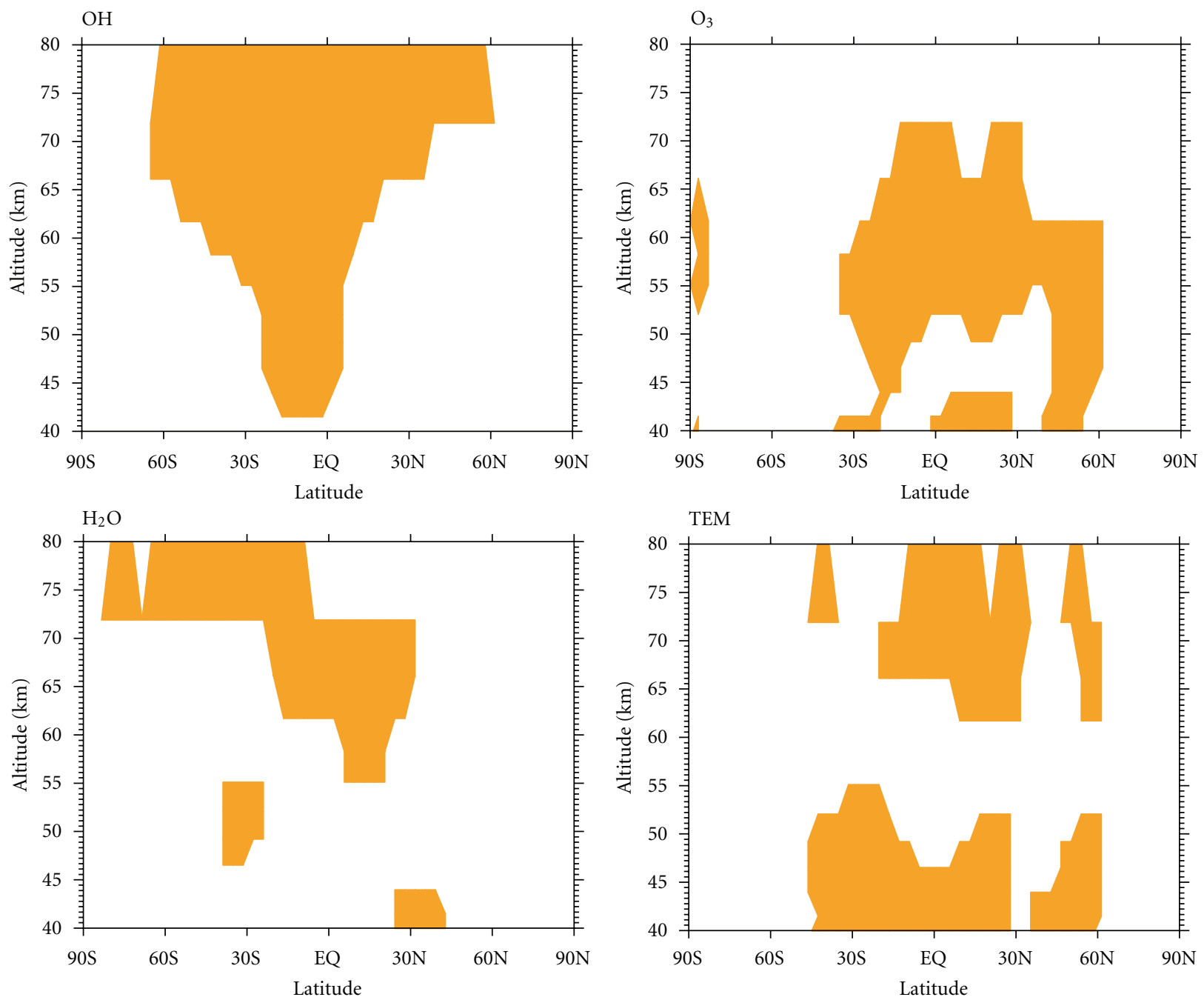

FIGURE 4: Areas where the nowcast and short-term forecasts of the considered quantities can be carried out with higher probability of the success.

correlate reasonably well with the time evolution of the solar irradiance shown in Figure 1. The simulated and observed ozone behaviors do not coincide completely, but it can be hardly expected because the satellite data have been collected during sunrise and the latitudes of data sampling are slightly different from day to day, while the simulated data represent daily and zonal mean values. However, the similar features are clearly visible in HALOE and simulated ozone, which supports our conclusions about potentially successful nowcast and short-term forecast of the ozone in this area.

\section{Conclusions and Outlook}

With the chemistry-climate model SOCOL, we simulated the time evolution of the temperature and several atmospheric constituents during January 1992 using solar UV irradiance observed by SUSIM instrument onboard UARS satellite. We have estimated the correlation between time series of the simulated quantities and solar irradiance at $205 \mathrm{~nm}$ and defined the area in the middle atmosphere where the UV solar variability is one of the main driving forces. Performed ensemble simulation of the atmospheric state allowed to define the level of noise due to nonlinear dynamics and connected with it transport of the species. Using the combination of these two limiting factors, we defined the area in the middle atmosphere where the nowcast and short-term forecast can be performed using our model with the highest level of success. Comparison of the simulated ozone behavior with observation data confirmed that successful nowcasting and short-term forecasting are possible inside the defined areas. It should be noted that our results are valid only for January 1992, when the variability of the solar irradiance was rather well pronounced and the meteorological conditions were typical for boreal winter season. Further studies are necessary to define these areas for different seasons and years. In the future, we intend to address this issue using CCM SOCOL driven by the highly accurate irradiance obtained from LYRA [5], PREMOS [20], and other real-time solar irradiance measurements that will be available in the future. The simulated results will be compared with time evolution 


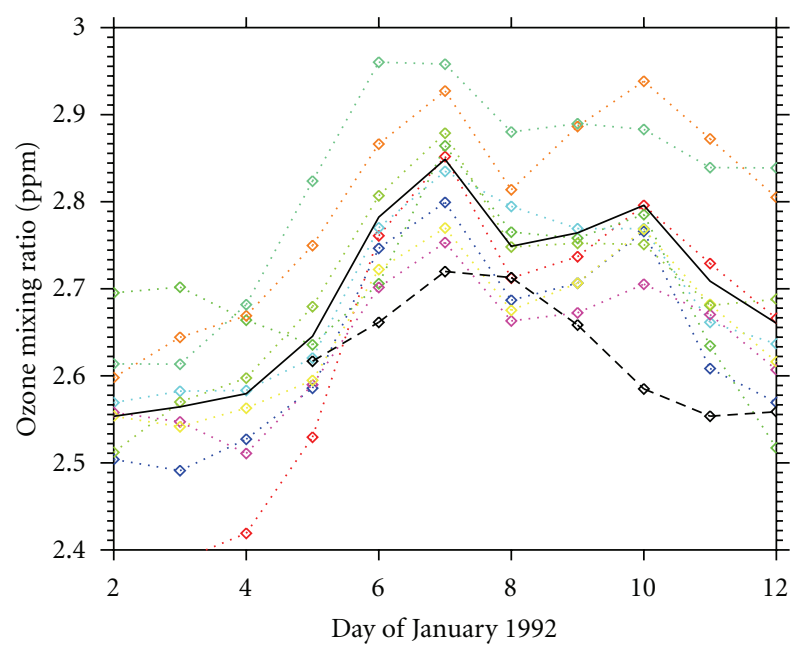

Figure 5: Zonal mean ozone volume mixing ratio (ppmv) at $48 \mathrm{~km}$ averaged over $40^{\circ} \mathrm{N}-50^{\circ} \mathrm{N}$ from HALOE data (dotted black line) and from the model results. The ensemble mean is shown by solid black line; color lines represent different ensemble members.

of the species obtained from the different data available from a variety of ongoing satellite missions. Another aspect which should be taken into account for the further studies is the influence of the particles entering the Earth's atmosphere during geophysical events.

\section{Acknowledgments}

The work leading to these results has received funding from the European Commission's Seventh Framework Programme (FP7/2007-2013) under the Grant agreement no. 218816 (SOTERIA project, http://www.soteria-space.eu) and Gebert-Rüf Foundation under Grant GRS-007/08. The project has also benefited from the travel support for the COST action ES0803. The work of A. V. Shapiro was supported by the funding from the Swiss National Science Foundation under Grant agreement no. 200020 130102. The work of E. Rozanov was supported by CRSI122-130642 (FUPSOL).

\section{References}

[1] D. C. Wilkinson, "National oceanic and atmospheric administration's spacecraft anomaly data base and examples of solar activity affecting spacecraft," Journal of Spacecraft and Rockets, vol. 31, no. 2, pp. 160-165, 1994.

[2] F. Jansen, R. Pirjola, and R. Favre, Space Weather: Hazard to the Earth? Swiss Re, Zurich, Switzerland, 2000.

[3] G. Brasseur and S. Solomon, Aeronomy of the Middle Atmosphere: Chemistry and Physics of the Stratosphere and Mesosphere, Springer, Dordrecht, The Netherlands, 3rd edition, 2005.

[4] G. E. Brueckner, K. L. Edlow, L. E. Floyd IV, J. L. Lean, and M. E. Vanhoosier, "The Solar Ultraviolet Spectral Irradiance Monitor (SUSIM) experiment on board the Upper
Atmosphere Research Satellite (UARS)," Journal of Geophysical Research, vol. 98, no. 6, pp. 10695-10711, 1993.

[5] J. F. Hochedez, W. Schmutz, Y. Stockman et al., "LYRA, a solar UV radiometer on proba2," Advances in Space Research, vol. 37, no. 2, pp. 303-312, 2006.

[6] W. K. Tobiska, T. Woods, F. Eparvier et al., "The SOLAR2000 empirical solar irradiance model and forecast tool," Journal of Atmospheric and Solar-Terrestrial Physics, vol. 62, no. 14, pp. 1233-1250, 2000.

[7] L. L. Hood, "Effects of solar UV variability on the stratosphere," in Solar Variability and Its Effect on Climate, J. Pap and P. Fox, Eds., vol. 141 of Geophysical Monograph Serries, pp. 283-3023, American Geophysical Union, Washington, DC, USA, 2004.

[8] E. Rozanov, T. Egorova, W. Schmutz, and T. Peter, "Simulation of the stratospheric ozone and temperature response to the solar irradiance variability during sun rotation cycle," Journal of Atmospheric and Solar-Terrestrial Physics, vol. 68, no. 18, pp. 2203-2213, 2006.

[9] T. Egorova, E. Rozanov, V. Zubov, E. Manzini, W. Schmutz, and T. Peter, "Chemistry-climate model SOCOL: a validation of the present-day climatology," Atmospheric Chemistry and Physics, vol. 5, no. 6, pp. 1557-1576, 2005.

[10] E. Manzini, N. A. McFarlane, and C. McLandress, "Impact of the Doppler spread parameterization on the simulation of the middle atmosphere circulation using the MA/ECHAM4 general circulation model," Journal of Geophysical Research D, vol. 102, no. 22, pp. 25751-25762, 1997.

[11] M. Charron and E. Manzini, "Gravity waves from fronts: parameterization and middle atmosphere response in a general circulation model," Journal of the Atmospheric Sciences, vol. 59, no. 5, pp. 923-941, 2002.

[12] E. V. Rozanov, V. A. Zubov, M. E. Schlesinger, F. Yang, and N. G. Andronova, "The UIUC three-dimensional stratospheric chemical transport model: description and evaluation of the simulated source gases and ozone," Journal of Geophysical Research D, vol. 104, no. 9, pp. 11755-11781, 1999.

[13] T. A. Egorova, E. V. Rozanov, V. A. Zubov, and I. L. Karol', "Model for investigating ozone trends (MEZON)," IzvestiyaAtmospheric and Ocean Physics, vol. 39, no. 3, pp. 277-292, 2003.

[14] V. A. Zubov, E. V. Rozanov, and M. E. Schlesinger, "Hybrid scheme for three-dimensional advective transport," Monthly Weather Review, vol. 127, no. 6, pp. 1335-1346, 1999.

[15] P. E. Gleckler, AMIP Newsletter, No. 7: AMIP-II Guidelines, Livermore National Laboratory, Livermore, Calif, USA, 1996.

[16] E. V. Rozanov, M. E. Schlesinger, and V. A. Zubov, "The University of Illinois, Urbana-Champaign three-dimensional stratosphere-troposphere general circulation model with interactive ozone photochemistry: fifteen-year control run climatology," Journal of Geophysical Research D, vol. 106, no. 21, pp. 27233-27254, 2001.

[17] A. V. Shapiro, E. Rozanov, A. I. Shapiro et al., "Signature of the 27-day solar rotation cycle in mesospheric $\mathrm{OH}$ and $\mathrm{H}_{2} \mathrm{O}$ observed by the Aura Microwave Limb Sounder," Atmospheric Chemistry and Physics Discussions, vol. 11, no. 10, pp. 2847728498, 2011.

[18] T. Y. W. Huang and G. P. Brasseur, "Effect of long-term solar variability in a two-dimensional interactive model of the middle atmosphere," Journal of Geophysical Research, vol. 98, no. 11, pp. 20413-20427, 1993. 
[19] T. Egorova, E. Rozanov, E. Manzini et al., "Chemical and dynamical response to the 11-year variability of the solar irradiance simulated with a chemistry-climate model," Geophysical Research Letters, vol. 31, no. 6, Article ID L06119, 2004.

[20] G. Thuillier, S. Dewitte, and W. Schmutz, "Simultaneous measurement of the total solar irradiance and solar diameter by the PICARD mission," Advances in Space Research, vol. 38, no. 8, pp. 1792-1806, 2006. 

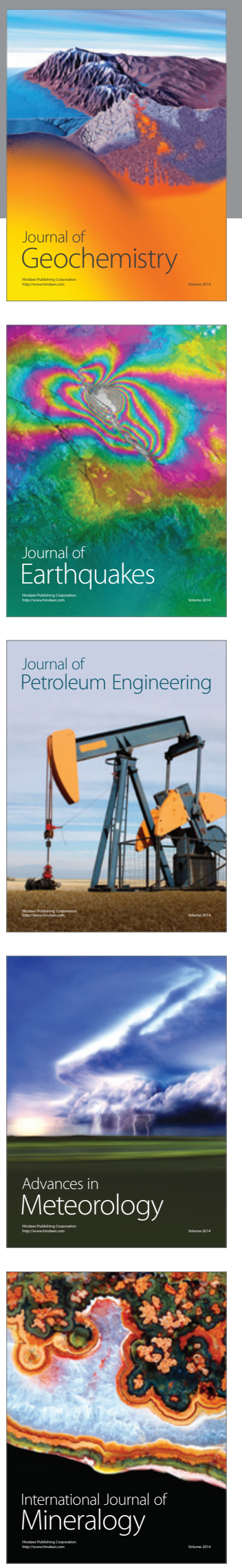
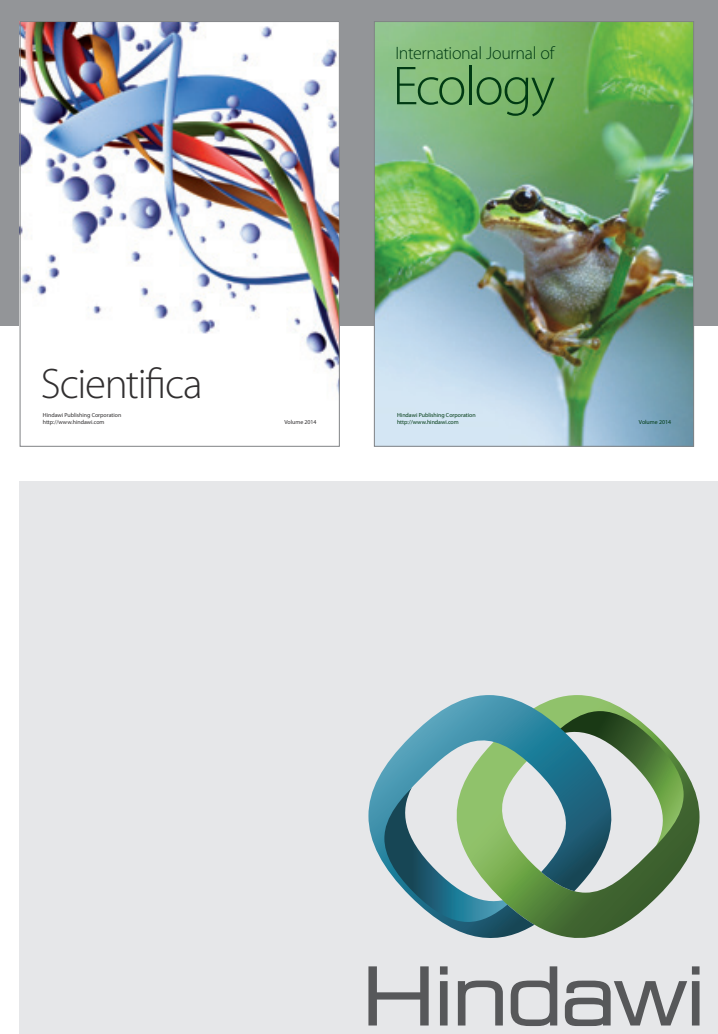

Submit your manuscripts at http://www.hindawi.com
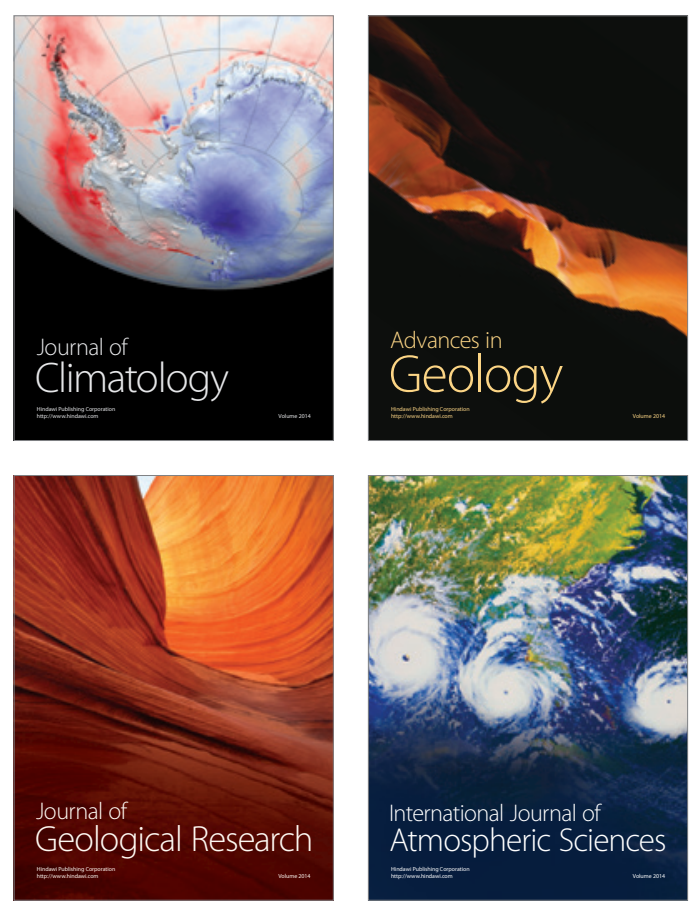
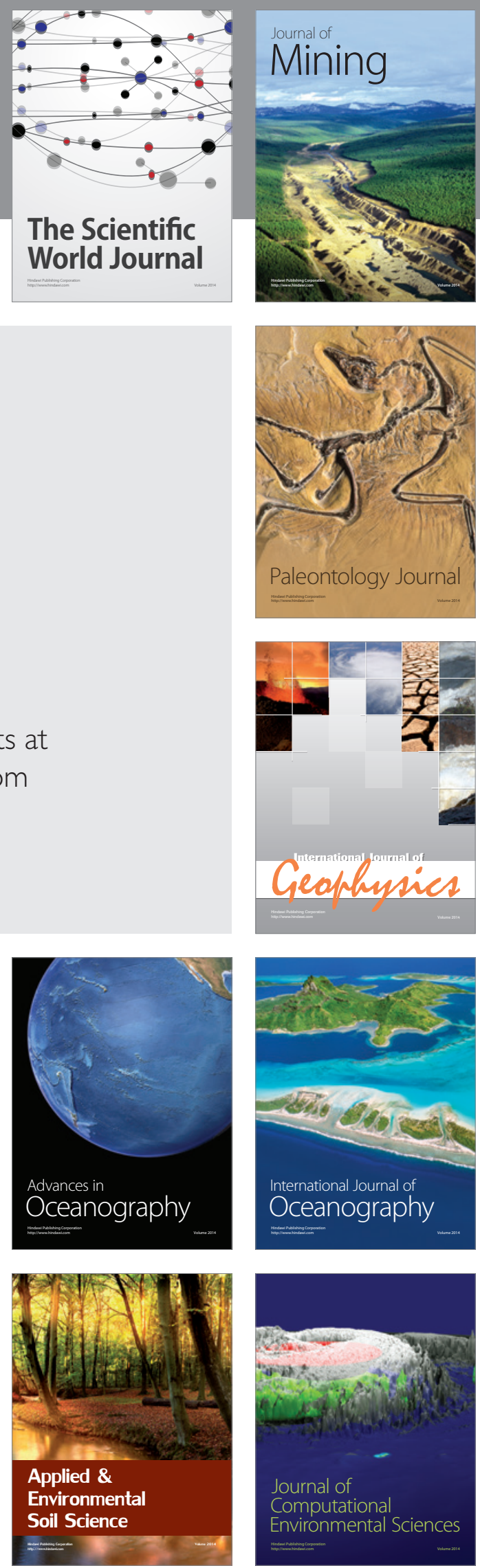